\title{
Case Report of a Very Rare and Interesting Case Report of Choroidal Melanoma Presenting as a Case of Acute Congestive Glaucoma Left Eye in a 55 Years Male
}

\author{
Gowhar Ahmad* \\ Department of ophthalmology, University of Jammu and Kashmir, India \\ *Corresponding author:Gowhar Ahmad, Department of ophthalmology, University of Jammu and Kashmir, India \\ Submission: 剕February 15, 2018; Published: 監April 06, 2018
}

\begin{abstract}
Choroidal melanomas are one of the commonest intra ocular tumors which are benign malignant pigmented or nor pigmented more common in whites as compared to blacks they have an early tendency of liver meatasis however if diagnosed and treated early one can prevent liver metatasis incidences 6 per million in USA 7.5 per million in Denmark and other Scandinavian countries. They are 89 percent choroidal 12 percent involve ciliary body and 8 percent involve iris they are difficult to diagnose due to their atypical presentations however in most of situations are seen as solid and exudative retinal detachments on funduscopy both direct and indirect and b scan ultrasound respectively out of these melanomas malignant melanoma of ciliary body yields poor results as far as treatment is concerned. Diagnostic modalities are as follows
\end{abstract}
1) Direct ophthalmoscopy
2) Indirect ophthalmoscopy
3) A scan ultrasound
4) B scan ultrasound
5) Ct scan brain
6) MRI scan brain
7) F f angiography

\section{Introduction}

As mentioned before the ch melanomas have atypical presentations which are as follows
A. Can be ant to lens
B. Involve angle of filtration
C. Involve vitreous
D. Sometimes severe ocular pain may be the only presentation

E. Very rarely the presentation may be sever fatigability

Loss of weight and appetite and loss of bladder control if they are ant to lens the clinical presentation is

I. Blurred vision
II. Progressive and painless visual field loss
III. Paracentral scotoma

If angle of filtration is involved the clinical presentation is
A. A c glaucoma
B. A a c glaucoma
C. Sec glaucoma
D. Ocular hypertension
E. Low tension glaucoma
F. Normal tension glaucoma
G. Pigmentory glaucoma 


\section{H. Neovascular glaucoma}

If vitreous is involved the clinical presentation is vitreous floaters treatment if the tumor is

i. 1 less than $12 \mathrm{~mm}$ observation

ii. If more than $12 \mathrm{~mm}$ enucleation

iii. Plaquebracopexy

iv. Radiotherapy

v. Chemotherapy

vi. Block section

vii. Pan retinal photocoagulation

viii. Pars plana vitrectomy

ix. Sometimes one may have to do exenteration

\section{Case report}

In 2011 a 55 years male patient presented with acute onset of sever left eye pain marked redness and sudden loss of vision it was a typical presentation of a $\mathrm{c}$ g glaucoma for which he received treatment from an emergency ophthalmological dept of medical college hospital in the form of 1 topical prostaglandin with

a. Timilol eye drops once

b. Dorzolamide with timilol eye drops twice

c. Topical steroid drops 4 times

d. Iv 500mg acetazolamide

e. Iv 500cc of 20 percent mannitol

However even after 8 to 10 hours of this medication pt did not show any improvement in his signs and symptoms however no b scan ultrasound left eye was done he was advised admission which was refused by him later he consulted other ophthalmologist for second opinion who performed b scan ultrasound and it showed a solid retinal detachment MRI scan brain was done for confirmation of choroidal melanoma but to the ill luck of both patient and ophthalmologist even after repeating the MRI the report was very unsatisfactory this created lot of confusion and pt started going from one ophthalmologist to other he was in this untreated stage for a period of 2 years i saw pt in 2013 left eye opaque media making the details of post segment difficult to visualize i performed b scan picked up solid retinal detachment MRI brain confirmed the radiological evidence of choroidal melanoma it also revealed normal optic nerve optic tract chiasma and radiatiobs also basal gangla were normal pituitary fossa and gland normal midbrain thalamic ventricles and cerebral hemispheres were normal ultrasound liver normal so on all these reports under $\mathrm{g}$ a i did block section by removing all the intraocular contents like cornea lens vitrous choroid and retina leaving behind iscleral cavity all extra ocular muscle attachments and underlying orbital adenexathe removed tissues were sent for histo pathological examination which did not reveal any evidence of malignancy in stitched the ant and post lips of sclera with 6 zero vicoryl kept a corrugated ruber drain in the intrascleral cavity for drainage of any secretions the drain was removed after 24 hours later i put a confirmer to increase the orbital volume the confirmer was removed after 15 days later a well fitting and well matching prosthesis was put by me in left socket [1-8].

\section{Discussion}

More than 4 years have passed pt is doing very well he is pain free and cosmetically he has a well fitting left eye prosthesis his repeat MRI brain is normal so is his ultrasound liver [9-15].

\section{Conclusion}

In conclusion we come to one important point that is if we come across a case of a c glaucoma which does not respond to treatment please do b scan ultrasound and MRI respectively and accordingly do the necessary treatment to support this statement $\mathrm{i}$ will put forward following

A. In institute of ophthalmology manchester London a pt choroidal melanoma presented as a c glaucoma did not respond to usual Anti-glaucoma medication the vision in other eye was 6 18 unaided pt did not respond to anti glaucoma medication MRI brain revealed choroidal melanoma so enucleaton was done.

B. In bascom palmar institute of ophthalmology university of miami florida 2 pts of choroidal melanomas presented with AAC glaucoma one pt was put on antiglucoma medication and later laser iridotomy was done the 2nd pt had hazy media making details of post segment difficult to be visualized giving a strong evidence od ocult intra ocular melanoma $b$ san and MRI were done which proved the diagnosis of ch melanoma so enucleation was done.

C. Sometimes choriodal melanoma may present as sec glaucoma in this context in university of cario dept of ophthalmology and pathology published in Saudi medical journal a pt of choroidal melanoma presented as sec glaucoma with an i o pof $56 \mathrm{~mm}$ hg did not respond to treatment MRI brain revealed choroidal melanoma so enucleation was done.

D. Malignant melanoma of ciliary body can present as ocular hypertension or chronic uvitis however this tumor yields poor results [15-19].

\section{References}

1. Augsburger JJ, Correa ZM, Shaikh AH (2009) Effectiveness of treatments formetastatic uveal melanomas. Am J ophthalmol 148(1): 119-127.

2. Augsburger JJ, Correa ZM, Trichopoulos N (2007) An alternative hypothesis or observed mortality rates due to metastasis after treatment of choroidal melanomas of different sizes. Trans Am Ophthalmol Soc 105: 54-59.

3. Bechrakis NE, Hocht S, Martus P, Kreusel KM, Heese J, et al (2004) Endoresection following proton beam irradiation of large uveal melanomas. Ophthalmologe 101(4): 370-376.

4. Bove R, Char DH (2004) Nondiagnosed uveal melanomas. Ophthalmology 111(3): 554-557. 
5. Collobrative Ocular Melanoma Study Group (2006) The COMS randomized trial of iodine 125 brachytherapy for choroidal melanoma: $\mathrm{V}$. Twelve-year mortality rates and prognostic factors; COMS report No. 28. Arch Ophthalmol 124(12): 1684-1693.

6. Damato B (2001) Detection of uveal melanoma by optometrists in the United Kingdom. Ophthalmic Physiol Opt 21(4): 268-271.

7. Damato b (2006) Treatment of primary intraocular melanoma. Expert Rev Anticancer Ther 6(4): 493-506.

8. Damato B, Coupland SE (2009) A reappraisal of the significance of largest basal diameter of post uveal melanoma. Eye 23(12): 2152-2160.

9. Damato B, Dopierala J, Kiaasen A, Van Dijk MC, Sibbring j, et al. (2009) Multiplex ligation dependent probe amplification of uveal melanoma. Correlation with metastatic death. Inves Ophthalmol Vis Sci 50(7): 3048-3055.

10. Damato B, Duke C, Coupland SE, Hiscott P, Smith PA, et.al (2007) Cytogenesis of uveal melanoma: A 7-year clinical experience. Ophthalmology 114(10): 1925-1931.

11. Daato B, Eieuten A, Fisher AC, Coupland SE, Taktak AF (2008) Artificial neural networks estimating survival probability after treatment of choroidal melanoma. Ophthalmology 115(9): 1598-1607.

12. Onken MD, Worley LA, Ehlers JP, Harbour JW (2004) Gene expression profiling in uveal melanoma reveals two molecular classes and predicts metastatic death. Cancer Res 64(20): 7205-7209.
13. Parrella P, Sidransky D, Merbs SL (1999) Allelotype of posterior uveal Melanoma: implicationsfor bifercated tumor progression pathway. Cancer Res 59(13): 3032-3037.

14. Prescher G, Bornfeld N, Hirche H, Horsthemke B, Jockel KH, et.al (1996) prognostic Implications of monosomy 3 in uveal melanoma. Lancet 347(9010): 1222-1225.

15. Straatsma BR, Diener-West M, Caldwell R, Engstrom RE (2003) Mortality after deferral of treatment or no treatment for choroidal melanoma. Am J Ophthalmol 136(1): 47-54 .

16. White VA, Chambers JD, Courtright PD, Chang WY, Horsman DE (1998) Correlation of cytogenic abnormalities with the outcome $\mathrm{f}$ patients with uveal melanoma. Cancer 83(2): 354-359.

17.Zimmerman LE, Mclean IW, Foster WD (1978) Does enucleation of the eye containing a malignant melanoma prevent or accelerate dissemination of tumour cells. Br J Ophthalmol 62(6): 420-425.

18. Voelter V, Schalenbourg A, Pampallona S, Peters S, Halkic N, et.al (2008) Adjuvant intra-arterial hepatic fotemustine for high-risk uveal melanoma patients. Melanoma Res 18(3): 220-224.

19. Tschentscher F, Husing J, Holter T, Kruse E, Dresen IG, et.al (2003) Tumor classification based on gene expression profiling shows that uveal melanomas with and without monosomy 3 represent two distint entities. Cancer Res 63(10): 2578-2584.

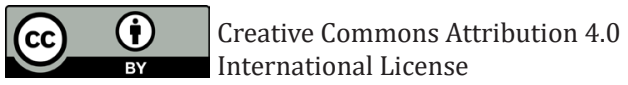

For possible submissions Click Here

\section{Submit Article}

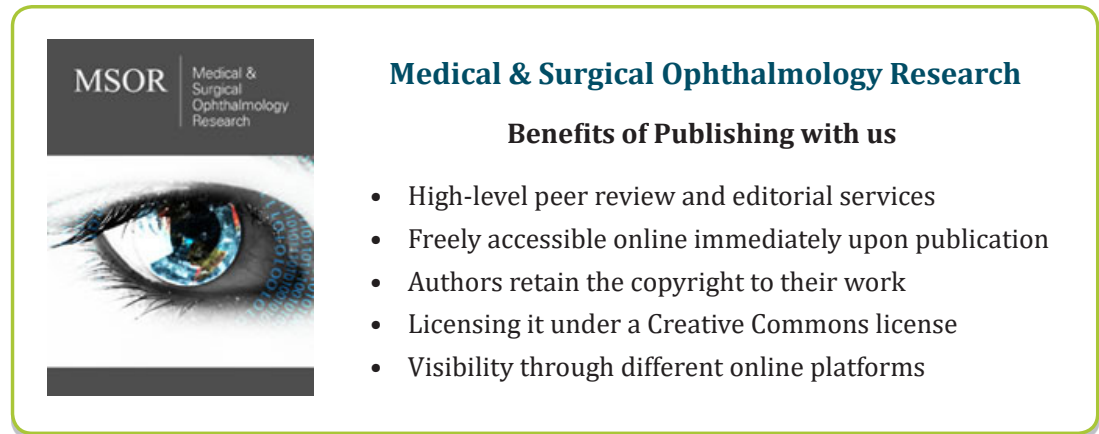

